\title{
UJI KUALITATIF MERKURI PADA KRIM PEMUTIH WAJAH YANG TIDAK TERDAFTAR BADAN PENGAWAS OBAT DAN MAKANAN DI KABUPATEN TULUNGAGUNG
}

\section{Qualitative Test Of Mercury In Unregistered Whitening Cream By National Agency of Drug and Food Control In Tulungagung}

\author{
1*Andyanita Hanif Hermawati, ${ }^{2}$ Qurrotu A'yunin Lathifah
}

\begin{abstract}
${ }^{1}$ Prodi Teknologi Laboratorium Medis STIKes Hutama Abdi Husada, Jl Dr Wahidin Sudiro Husodo, Tulungagung, Indonesia
${ }^{2}$ Prodi Teknologi Laboratorium Medis STIKes Hutama Abdi Husada, Jl Dr Wahidin Sudiro Husodo, Tulungagung, Indonesia
\end{abstract}

*e-mail : andya.nita@yahoo.com

\begin{abstract}
ABSTRAK
Krim yang digunakan untuk mencerahkan kulit dan memudarkan noda hitam yaitu krim pemutih wajah. Merkuri merupakan bahan aktif yang biasanya digunakan dalam krim pemutih wajah. Penggunaan salah satu zat berbahaya pada kosmetik yaitu merkuri. Iritasi, gangguan syaraf, gatal, sampai kanker kulit merupakan akibat dari penggunaan merkuri pada krim pemutih wajah. Penelitian ini bertujuan untuk mengetahui ada tidaknya merkuri dengan uji kualitatif pada sediaan krim pemutih wajah yang tidak terdaftar Badan Pengawas Obat dan Makanan (BPOM) di Kabupaten Tulungagung. Jenis penelitian ini menggunakan penelitian deskriptif. Jumlah sampel krim pemutih wajah yang tidak terdaftar Badan Pengawas Obat dan Makanan (BPOM) di Kabupaten Tulungagung sejumlah 6 sampel. Uji warna menggunakan larutan KI 0,5 N merupakan uji kualitatif merkuri. Hasil penelitian dengan uji kualitatif menunjukkan semua sampel negatif mengandung merkuri.
\end{abstract}

Kata kunci : Krim Pemutih Wajah, Merkuri, Uji Warna, Kualitatif

\section{ABSTRACT}

The cream used to brighten up skin and fades freckles of face is called whitening cream. Mercury is the active ingredient that is commonly used in face whitening cream. The use of hazardous substances in cosmetics namely mercury. Irritation, nervous disorders, itching, until skin cancers are the result of the use of mercury in whitening cream. This research aims to find out whether there is mercury or not by qualitative test in whitening cream which is unregistered by Badan Pengawas Obat dan Makanan (BPOM) in Tulungagung. The type of this research is descriptive research. The number of whitening cream samples which is unregistered by Badan Pengawas Obat dan Makanan (BPOM) Tulungagung as many as 6 samples. Colour test used $0.5 \mathrm{~N}$ KI solution is qualitative test of mercury. Results of the study with qualitative test shows that all negative samples contain mercury.

Keyword: Whitening cream, Mercury, Colour test, Qualitative

\section{PENDAHULUAN}

Organ terluar dari tubuh yang melapisi seluruh tubuh manusia yaitu kulit. Pembentukan pigmen melanin merupakan mekanisme biologis untuk melindungi kulit dari bahaya sinar ultraviolet. Kulit berfungsi sebagai perlindungan dari berbagai gangguan dan rangsangan luar. Setiap wanita mendambakan kulit putih dan cerah. Bagi wanita modern hal ini menjadi trend masa kini sehingga salah satu langkah yang dilakukan yaitu pemakaian krim pemutih wajah (Trisnawati et al, 2016).
Wajah yang memiliki berbagai masalah dengan menggunakan krim pemutih maka mampu mengembalikan kecerahan kulit dan mengurangi warna hitam pada wajah (Parengkuan et al, 2013). Kegunaan krim pemutih dapat memutihkan kulit atau memudarkan noda hitam pada kulit dengan campuran bahan kimia dan atau bahan lainnya. Merkuri merupakan salah satu bahan aktif yang biasanya digunakan dalam krim pemutih. Air raksa $(\mathrm{Hg})$ disebut juga merkuri termasuk dalam golongan logam berat dengan bentuk cair dan berwarna 
keperakan (Sembel, 2015; Trisnawati, 2016). Merkuri dalam kadar yang sedikitpun bersifat racun berdasarkan PERMENKES RI No.445/MENKES/PER/V/1998 tentang bahan, zat warna, substrat, zat pengawet, dan tabir surya pada kosmetik (Budiman et al, 2015).

Krim pemutih yang mengandung merkuri dapat berakibat dari berbagai hal, diantaranya mengakibatkan warna kulit yang berubah. Perubahan warna kulit diantaranya yaitu alergi, timbul bintikbintik hitam pada kulit, dan iritasi kulit. Pemakaian merkuri dengan dosis tinggi pada krim pemutih wajah dapat mengakibatkan kerusakan permanen ginjal, otak, dan gangguan perkembangan janin. Bahkan, paparan dalam jangka pendek juga dapat menyebabkan diare, muntah-muntah, dan kerusakan paru-paru serta merupakan zat karsinogenik pada manusia (BPOM, 2006).

Berdasarkan penelitian Trisnawati et al (2016), menunjukkan tidak semua krim pemutih wajah memenuhi syarat yang telah ditetapkan oleh Badan Pengawas Obat dan Makanan (BPOM). Krim pemutih wajah tersebut beredar di Pasar DTC Wonokromo Surabaya. Hasil penelitian menunjukkan 2 dari 18 sampel mengandung merkuri berdasarkan uji kuantitatif menunjukkan kadar merkuri pada produk krim pemutih yang terdaftar di Badan Pengawas Obat dan Makanan (BPOM) sebesar $224,04 \pm 0,35 \mathrm{mg} / \mathrm{kg}$ dan $188,20 \pm 0,28 \mathrm{mg} / \mathrm{kg}$. Hasil pemeriksaan ditemukan bahwa sampel termasuk dalam daftar produk yang dibatalkan izin edarnya di pasaran.

Berdasarkan hasil survey yang dilakukan oleh peneliti terdapat toko yang menjual berbagai kosmetik salah satunya krim pemutih wajah. Krim pemutih wajah tersebut tidak terdaftar Badan Pengawas Obat dan Makanan (BPOM) dan ada sebagian krim yang tidak terdapat komposisinya. Krim pemutih wajah tersebut dijual dengan harga yang relatif murah dan banyak diminati masyarakat. Oleh karena itu, peneliti ingin menguji secara kualitatif kandungan merkuri pada krim pemutih yang tidak terdaftar di Badan Pengawas Obat dan Makanan (BPOM) yang beredar di Kabupaten Tulungagung sehingga dapat diketahui apakah krim tersebut memenuhi persyaratan yang telah ditetapkan.

\section{METODE PENELITIAN}

Alat

Alat yang digunakan dalam penelitian ini yaitu gelas ukur, labu ukur, pipet volume, rak tabung, erlenmeyer, kertas saring, pipet tetes, batang pengaduk, tabung reaksi, dan neraca elektrik.

\section{Bahan}

Bahan yang digunakan adalah asam klorida $(\mathrm{HCl})$, asam nitrat $\left(\mathrm{HNO}_{3}\right)$, aquades $\left(\mathrm{H}_{2} \mathrm{O}\right)$, kalium iodide (KI), dan 6 sampel krim pemutih.

\section{Pembuatan Larutan KI 0,5 N}

Ditimbang kalium iodida (KI) sebanyak 2 gram. Dimasukkan ke dalam labu ukur $25 \mathrm{ml}$. Ditambahkan aquadest $\left(\mathrm{H}_{2} \mathrm{O}\right)$ sampai tanda $25 \mathrm{ml}$ lalu dikocok hingga homogen.

\section{Pembuatan Larutan Uji :}

Ditimbang sampel sebanyak 2 gram. Ditambahkan aquadest $\left(\mathrm{H}_{2} \mathrm{O}\right)$ sebanyak $25 \mathrm{ml}$. Ditambahkan dengan campuran $10 \mathrm{ml}$ asam klorida $(\mathrm{HCl})$ dan asam nitrat $\left(\mathrm{HNO}_{3}\right)$. Diuapkan sampai hampir kering. Pada sisa penguapan ditambahkan aquades sebanyak $10 \mathrm{ml}$. Dipanaskan sebentar lalu dinginkan dan disaring.

\section{Uji Kualitatif}

Dipipet $1 \mathrm{ml}$ larutan uji dimasukkan dalam tabung reaksi. Ditambahkan 1-2 tetes larutan KI 0,5 N. Dihomogenkan lalu diperhatikan dengan seksama. Hasil positif jika terjadi endapan merah orange.

\section{HASIL DAN PEMBAHASAN}

Hasil uji kualitatif merkuri pada krim pemutih wajah yang tidak terdaftar Badan Pengawas Obat dan Makanan (BPOM) di Kabupaten Tulungagung disajikan dalam Tabel 1, Tabel 2, Gambar 1, dan Gambar 2.

TABEL 1. Hasil Uji Warna Pemeriksaan Krim Pemutih Wajah Menggunakan Kalium Iodida (KI) 0,5 N

\begin{tabular}{ccl}
\hline No. & Nama Sampel & \multicolumn{1}{c}{ Hasil Warna } \\
\hline 1. & Krim A & Putih \\
\hline 2. & Krim B & Putih \\
\hline 3. & Krim C & Kuning Tua \\
\hline 4. & Krim D & Kuning Kemerahan \\
\hline 5. & Krim E & Putih \\
\hline 6 & Krim F & Kuning Pucat \\
\hline
\end{tabular}

Berdasarkan Tabel 1 diketahui bahwa keenam sampel krim pemutih wajah yang tidak terdaftar Badan Pengawas Obat dan Makanan (BPOM) di 
Kabupaten Tulungagung setelah direaksikan dengan larutan KI 0,5 $\mathrm{N}$ memiliki warna yang berbeda-beda yaitu putih, kuning tua, kuning kemerahan dan kuning pucat.

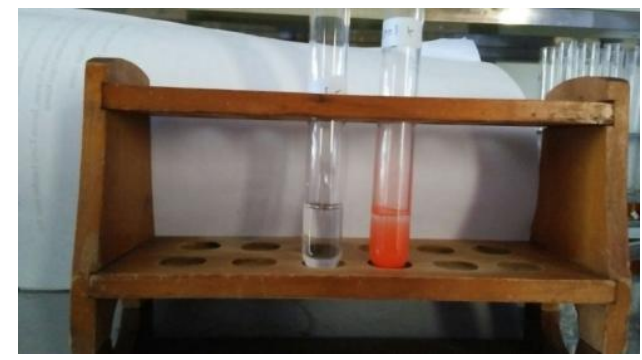

Gambar 1. Hasil Kontrol Negatif (-) dan Kontrol Positif (+)

Berdasarkan uji warna yang telah dilakukan terhadap krim C, D, dan F tidak sesuai kontrol negatif setelah ditambahkan larutan KI 0,5 N sedangkan krim A, B, dan E setelah ditambahkan larutan KI 0,5 $\mathrm{N}$ tetap jernih seperti kontrol negatif (-).

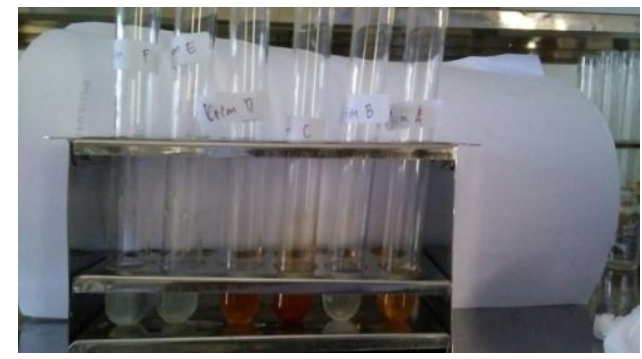

Gambar 2. Hasil Uji Warna Pemeriksaan Krim Pemutih Wajah yang Tidak Terdaftar BPOM Menggunakan Kalium Iodida (KI) $0,5 \mathrm{~N}$

Krim C setelah ditambahkan KI menjadi kuning tua, krim D menjadi kuning kemerahan, dan krim $\mathrm{F}$ menjadi kuning pucat. Krim $\mathrm{C}, \mathrm{D}$, dan F mungkin terdapat senyawa lain seperti hidrokuinon, retin A, dan Rhodamin B karena sampel tersebut setelah direaksikan dengan KI memiliki warna yang berbeda-beda.

TABEL 2. Distribusi Hasil Analisa Merkuri Pada Krim Pemutih Wajah Yang Tidak Terdaftar BPOM di Kabupaten Tulungagung

\begin{tabular}{|c|c|c|c|}
\hline No. & $\begin{array}{c}\text { Nama } \\
\text { Sampel } \\
\end{array}$ & $\begin{array}{c}\text { Positif } \\
\text { Merkuri }\end{array}$ & $\begin{array}{c}\text { Negatif } \\
\text { Merkuri }\end{array}$ \\
\hline 1. & Krim A & & $\sqrt{ }$ \\
\hline 2. & Krim B & & $\sqrt{ }$ \\
\hline 3. & Krim C & & $\sqrt{ }$ \\
\hline 4. & Krim D & & $\sqrt{ }$ \\
\hline 5. & Krim E & & $\sqrt{ }$ \\
\hline 6. & Krim F & & $\sqrt{ }$ \\
\hline
\end{tabular}

Berdasarkan Tabel 2 diketahui bahwa keenam sampel krim pemutih wajah yang tidak terdaftar Badan Pengawas Obat dan Makanan (BPOM) di Kabupaten Tulungagung tidak mengandung merkuri.

Pemeriksaan merkuri pada krim pemutih wajah yang tidak terdaftar Badan Pengawas Obat dan Makanan (BPOM) di Kabupaten Tulungagung dilakukan di Laboratorium Kimia STIKes Hutama Abdi Husada Tulungagung. Jumlah sampel dari penelitian ini sebanyak 6 sampel krim pemutih wajah yang tidak mencantumkan nomor registrasi Badan Pengawas Obat dan Makanan (BPOM) dan diberi kode A, B, C, D, E, dan F. Teknik sampling dalam penelitian ini adalah teknik total sampling.

\section{Berdasarkan PERMENKES}

No.445/MENKES/PER/V/1998, tentang daftar bahan, zat warna, substratum, zat pengawet, dan tabir surya pada kosmetik bahwa raksa dan senyawanya dilarang digunakan dalam kosmetik. Salah satu uji yang dapat dilakukan untuk mengetahui apakah krim pemutih wajah yang beredar di masyarakat terjamin aman digunakan yaitu melskukan pemeriksaan merkuri pada krim pemutih wajah.

Krim terdiri dari emulsi minyak dalam air atau dispersi mikrokristal asam-asam lemak atau alkohol berantai panjang dalam air yang dapat dicuci dengan air dan lebih ditujukan untuk pemakaian kosmetika dan estetika (Anief, 2000 dalam Gianti, 2013).

Merkuri anorganik yang biasanya digunakan di kosmetik krim biasa adalah ammoniated mercury. Penggunaan bahan pemutih kulit dalam sediaan krim yaitu Ammoniated mercury karena memiliki efek pemucat warna kulit. Pada kulit daya pemutih yang sangat kuat karena toksisitasnya terhadap organorgan ginjal, saraf dan otak sangat kuat sehingga pemakaiannya dilarang dalam sediaan kosmetik (WHO, 2011).

Pemeriksaan merkuri (raksa) pada krim pemutih wajah sampel harus didestruksi terlebih dahulu karena merkuri adalah senyawa anorganik. Destruksi adalah proses pemanasan suatu zat (padat) organik kompleks hingga terurai dan menghasilkan produk yang lebih sederhana (Rivai, 1995 dalam Rasyid, 2015). Bahan dalam kosmetik berbahaya mempunyai sifat yang tidak dapat larut dalam air (non polar) sehingga diperlukan destruksi terlebih dahulu. Pada tahapan ini sampel didestruksi dengan cara menimbang sampel sebanyak 2 gram, 
ditambahkan air sebanyak $25 \mathrm{ml}$, ditambahkan dengan campuran $10 \mathrm{ml}$ asam klorida dan asam nitrat, lalu diuapkan sampai hampir kering.

Sampel direaksikan dengan larutan KI 0,5 N setelah didestruksi untuk menentukan kandungan merkuri (raksa) dalam sediaan krim pemutih wajah secara kualitatif. Uji warna yang dilakukan bertujuan untuk mengetahui ada atau tidaknya merkuri dalam sampel krim pemutih wajah. Analisa kualitatif dilakukan dengan menambahkan 1-2 tetes larutan KI 0,5. Sampel krim pemutih wajah yang positif mengandung merkuri membentuk endapan merah bata sampai orange apabila ditetesi larutan KI 0,5 N. Endapan tersebut merupakan hasil reaksi antara $\mathrm{Hg}$ dalam krim pemutih wajah dengan KI sehingga membentuk $\mathrm{HgI}_{2}$ yang berwarna orange dan akan hilang pada penambahan KI berlebihan karena terbentuk senyawa komplek $\mathrm{K}_{2} \mathrm{HgI}_{4}$ larut (Ardan, 2016).

Hasil uji warna dari 6 sampel yang diuji tidak ada kandungan merkuri karena pada sampel tidak menunjukkan adanya endapan merah orange. Hal ini sesuai dengan penelitian Budiman (2016) yang menunjukkan hasil uji kualitatif sampel krim pemutih wajah tidak mengandung merkuri karena pada sampel tidak menunjukkan adanya endapan merah orange.

Pada umumnya bahan dalam kosmetik yang berbahaya mempunyai sifat yang tidak dapat larut dalam air (non polar) sehingga bahan-bahan tersebut akan tetap menempel pada kulit serta menumpuk di kulit. Pemakaian jangka panjang dapat mengakibatkan efek iritasi, gatal, gangguan syaraf sampai menyebabkan kanker kulit (BPOM, 2006).

Berdasarkan analisa kualitatif yang telah dilakukan dapat disimpulkan bahwa sampel krim pemutih wajah yang tidak terdaftar Badan Pengawas Obat dan Makanan (BPOM) di Kabupaten Tulungagung tidak mengandung merkuri. Sampel krim tersebut mungkin terdapat Hidrokuinon, Rhodamin B atau Retin A karena berdasarkan Badan Pengawas Obat dan Makanan (BPOM) sampel krim tersebut termasuk bahaya untuk digunakan karena tidak terdaftar nomor registrasi Badan Pengawas Obat dan Makanan (BPOM) dan tidak ada komposisi pada kemasan sehingga krim tersebut belum jelas komposisinya sesuai dengan standar yang telah ditetapkan oleh Badan Pengawas Obat dan Makanan (BPOM) atau tidak.

\section{KESIMPULAN}

Berdasarkan hasil penelitian dapat disimpulkan bahwa dari uji kualitatif sampel krim pemutih wajah yang tidak terdafar Badan Pengawas Obat dan Makanan (BPOM) di Tulungagung diketahui negatif mengandung merkuri. Peneliti selanjutnya diharapkan melakukan penelitian serupa dengan parameter lain seperti Hidrokuinon, Rhodamin B, dan Retin A.

\section{DAFTAR PUSTAKA}

Ardan, M., Agustina, R., \& Masruhim, M. 2016. Analisis Bahan Kimia Berbahaya Pada Krim Pencerah Wajah Yang Beredar Di Kota Samarinda. Prosiding Seminar Nasional Kefarmasian Ke-3, Samarinda, Fakultas Farmasi Universitas Mulawarman.

BPOM. 2006. Kosmetik Yang Mengandung Bahan dan Zat Warna Yang Dilarang. Jakarta.

Budiman, S., Afifah, H., Hadisubroto, G., \& Suryasaputra, D. 2015. Analisis Uji Kualitatitif Merkuri Pada Sediaan Krim Pemutih yang Beredar di Kota Bandung.. Seminar Nasional Farmasi (SNIFA) UNJANI.

Gianti. 2013. Analisis Kandungan Merkuri Dan Hidrokuinon Dalam Kosmetik Krim Racikan Dokter. Skripsi. UIN Syarif Hidayatullah, Jakarta.

Parengkuan, K., Fatimawali, F., \& Citraningtyas, G. 2013. Analisis Kandungan Merkuri Pada Krim Pemutih yang Beredar Di Kota Manado, Pharmacon Jurnal Ilmiah Farmasi. 2(1).

Rasyid, R., Susanti, E., Azhar, R. 2015. Pemeriksaan Kualitatif Hidrokuinon dan Merkuri Dalam Krim Pemutih. Jurnal Farmasi Higea. 7(1).

Tranggono, I.S.R., Fatma Latifah. 2014. Buku Pegangan Dasar Kosmetologi. Jakarta, Sagung Seto.

Trisnawati, A., Yulianti, H., \& Ebtavanny, G. 2016. Identifikasi Andungan Merkuri Pada Beberapa Krim Pemutih Yang Beredar Di Pasaran (Studi Dilakukan Di Pasar DTC Wonokromo 


\section{BJMLT}

Surabaya). Journal Pharmasci (Journal Of

Pharmacy And Science). ISSN : 2527-6328.

World Health Organization. 2011. Mercury In

Lightening Produsts. Public Health And

Environment, Switzerland. 